\title{
Between the city and the farm: food environments in artisanal mining communities in Upper Guinea
}

\author{
Stella Nordhagen ${ }^{1,2, *} \oplus$, Mohamed L Fofana ${ }^{3}$, Alpha O Barry ${ }^{4}$, Sadio Diallo ${ }^{4}$, \\ Joseph L Songbono ${ }^{4}$, Ronald Stokes-Walters ${ }^{5,6}$, Laetitia X Zhang ${ }^{5}$, Rolf Klemm ${ }^{2,5}$ and \\ Peter J Winch ${ }^{5}$ (1) \\ 'Global Alliance for Improved Nutrition (GAIN), Rue Varembé 7, Geneva 1202, Switzerland: ${ }^{2}$ Helen Keller \\ International, Washington, DC, USA: ${ }^{3}$ Helen Keller International Guinea, Landreah, Dixinn Corniche, Conakry,

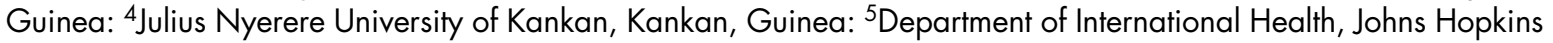 \\ Bloomberg School of Public Health, Baltimore, MD, USA: ${ }^{6}$ Action Against Hunger USA, New York, NY, USA
}

Submitted 28 April 2020: Final revision received 16 April 2021: Accepted 6 May 2021: First published online 12 May 2021

\begin{abstract}
Objective: Artisanal and small-scale mining (ASM) is a widespread livelihood in low- and middle-income countries; however, many in ASM communities face high levels of poverty and malnutrition. The food environments in ASM communities have non-agricultural rural characteristics that differ from those in urban and agricultural rural areas examined in much existing food environment literature. Design: We examine these complex external and personal food environments in ASM communities via a study using qualitative and quantitative methods. Market surveys and a cross-sectional household survey, plus qualitative mining site non-participant observations and in-depth structured interviews, were conducted in three waves.

Setting: Eighteen study sites in ASM communities in northern Guinea.

Participants: Surveys covered mothers in mining households with young children ( $n$ 613); in-depth interviews engaged caregivers of young children ( $n 45)$, food vendors ( $n$ 40) and young single miners ( $n$ 15); observations focused on mothers of young children ( $n$ 25).

Results: The external food environment in these ASM communities combines widespread availability of commercially processed and staple-heavy foods with lower availability and higher prices for more nutritious, non-staple foods. Within the personal food environment, miners are constrained in their food choices by considerable variability in daily cash income and limited time for acquisition and preparation.

Conclusions: We demonstrate that ASM communities have characteristics of both urban and rural populations and argue for greater nuance and appreciation of complexity in food environment research and resultant policy and programming.
\end{abstract}

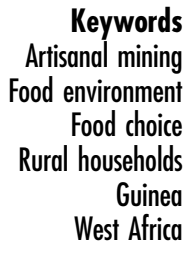

There is increasing recognition of the food environment's role in shaping food choices ${ }^{(1-5)}$. It is within the food environment that people obtain and consume foods, and food environment interventions can potentially have larger reach than attempts to change personal behaviours. ${ }^{(5)}$ Despite the importance of the food environment for consumers everywhere, most food environment research has examined food environments in high-income countries ${ }^{(6)}$. However, populations in low- and middle-income countries (LMIC) face large burdens of undernutrition as well as growing prevalence of overweight/obesity ${ }^{(7)}$, with potentially serious negative consequences for health and well-being ${ }^{(8)}$.

Examining food environments in LMIC, researchers commonly examine one of two scenarios: urban populations $^{(9,10)}$ or rural subsistence-agricultural households ${ }^{(11,12)}$. For the former, food choice is shaped by cash income and market food availability and prices - i.e. the external food environment, which is recognised to be dynamic and complex in urban areas, and sometimes associated with urbanisation itself ${ }^{(13-15)}$. In the latter, food choice is shaped by the household's own production, ability to 
sell/store surplus production and purchase of additional food with agricultural income - normally raw ingredients, as opposed to prepared foods.

The changing nature of food systems is blurring the divisions between 'urban' and 'rural' food environments and 'traditional' and 'modern' food systems ${ }^{(16)}$. Food now travels through longer supply chains, spanning rural and urban areas, with greater levels of processing, packaging and marketing ${ }^{(16-18)}$. Markets are important sources of food for rural populations ${ }^{(18-21)}$, and agriculture in urban areas is widespread across many African cities ${ }^{(22)}$. Both undernutrition and overweight/obesity now span urban and rural zones $^{(16)}$, with overweight/obesity levels rising fastest in rural areas ${ }^{(23)}$. These overlapping characteristics suggest increasing complexity and fluidity of rural food environments. However, rural areas where non-agricultural livelihoods are common have rarely been considered in food environment research; by considering only certain aspects of typical rural and urban areas, researchers may not have fully elucidated those qualities relevant to both.

In this paper, we delve into this complexity through a study of artisanal mining communities in Guinea - areas fusing rich mineral resources with widespread poverty and malnutrition. Drawing on data from a multi-phase study, we demonstrate that these communities blend urban and rural characteristics, with complex food environments that cannot be easily categorised within the typologies described by prior research ${ }^{(24)}$. This paper adds to a small literature on food environments in LMIC $^{(6)}$, bringing methodological diversity and a new focus on non-agricultural rural settings. It also adds to the literature on socioeconomic aspects and consequences of resource extraction livelihoods ${ }^{(25-29)}$ and can inform discussions of nutrition changes during structural transformation of rural areas, in which households tend to allocate more time to off-farm labor, such as mining ${ }^{(30)}$.

\section{Food environments and food choice}

Building on earlier conceptual work ${ }^{(20,31-33)}$, Turner et al. define the food environment as, 'the interface that mediates people's food acquisition and consumption within the wider food system (encompassing) external dimensions such as availability, prices, vendor and product properties, and promotional information; and personal dimensions such as the accessibility, affordability, convenience and desirability of food sources and products ${ }^{(34)}$.' The external dimensions reflect absolute characteristics applicable to all, whereas the internal dimensions are specific to the individual. For example, availability refers to a food's presence; for individuals, this translates into accessibility based on time availability and mobility. Similarly, prices translate into affordability, vendor/product properties map onto convenience and marketing/regulation affect desirability ${ }^{(34)}$.
Empirical work on food environments has focused on high-income countries and, within those, primarily on urban areas and issues related to obesity/overweight ${ }^{(35-38)}$. Work in LMIC has been limited, despite numerous differences with high-income countries - such as more informal retailers, greater price volatility, less advertising/labelling and limited regulation. A recent review of food environment research in LMIC found that no articles examined low-income countries and most (70\%) focused on upper-middle-income countries $^{(6)}$. Only half of studies considered both external and personal food environments, and only $11 \%$ used mixed methods. Moreover, only five of 70 studies focused on specific rural areas ${ }^{(11,39-42)}$. Of those, four focused on Latin America; two considered agricultural communities, while the remaining three offered no details on livelihoods. A recent categorisation of food environments also largely omitted non-agrarian rural settings ${ }^{(24)}$. There is thus a gap in research on food environments in rural LMIC, particularly for rural non-agricultural households and low-income African countries.

\section{Artisanal and small-scale mining}

Artisanal and small-scale mining (ASM) is a growing livelihood supporting approximately 100 million people in eighty LMIC, typically practiced by poor, under-educated populations in rural areas ${ }^{(43)}$. Artisanal miners generally work independently and informally, with rudimentary techniques, poor conditions and low returns ${ }^{(44)}$. In Guinea, ASM is estimated to engage $222000-300000$ people and financially support about $1.3-1.5$ million $-12 \%$ of the population ${ }^{(26,45)}$. In the country's northeast, mining (particularly of gold) is a major economic activity. Men, women and children all participate ${ }^{(46-48)}$, with women estimated to comprise up to $74 \%$ of small-scale miners in Guinea, usually in less well-paid roles ${ }^{(47,49)}$.

While ASM can be a route to reduced poverty/ vulnerability ${ }^{(49-51)}$, many enter the sector because of hardship; most are poor former or concurrent subsistence farmers ${ }^{(26)}$. ASM is associated with numerous environmental and health risks, including malnutrition. The region studied here has stunting levels among children under 5 years (30.5\%) on par with the national average but the country's second-highest prevalence of wasting among under-fives (10.7\%); among women (ages 15-49 years), 6.7\% are underweight and $24.6 \%$ are overweight/obese, based on standard BMI cutoffs ${ }^{(52)}$. Nutritious food may be hard to access due to high costs, limited options for producing/ purchasing, seasonality and time constraints. Mining sites may become host to temporary shanty towns, with scant resources and damaged soils or water unsuitable for agriculture $^{(44,53,54)}$. Fresh food access may be further limited if agriculture is displaced by mining ${ }^{(26,55,56)}$.

Given certain characteristics associated with urban populations - e.g. access to cash, purchasing most food - ASM areas exemplify food environments mixing 
urban and rural characteristics. This agriculture-to-mining transition is also representative of larger shifts from locally focused agricultural livelihoods to (peri-)urban living and unstable livelihoods dependent on global markets ${ }^{(57,58)}$, with concomitant shifts in food environments, diets and nutrition $^{(24,59)}$.

There has been little study of food and nutrition within ASM communities. A spatial modelling study in Democratic Republic of Congo found high malnutrition rates in provinces reliant on mining ${ }^{(60)}$. An analysis of data from thirty-eight African countries showed that internationally operated industrial mines are associated with decreased food availability among women (but not men) and lower children's dietary diversity but did not consider $\mathrm{ASM}^{(61)}$. Researching Guinean bauxite miners, Dabo reported that women saw mining as causing maternal and child malnutrition(53). Examining ASM in Mali, Keita noted that, amid a cereal-based diet, high consumption of low-quality canned foods, unhygienic conditions and intensive energy expenditure, malnutrition was prevalent ${ }^{(62)}$. Tschakert mentioned that Ghana's artisanal gold miners saw poor quality and limited food as problems with mining ${ }^{(63)}$. In contrast, Grätz cited miners' excessive food consumption in boom times in Benin ${ }^{(25)}$. Finally, Maconachie and collaborators examined connections between agriculture and ASM in Sierra ${ }^{(28,51,64-66)}$. None of these authors, however, examined nutrition or food environments further.

\section{Methods}

Research was conducted in Kouroussa and Siguiri prefectures, Kankan region, Guinea. Study sites were selected purposively to cover four different strata: temporary mining camps, villages far from towns, villages close to towns and towns. Stratification was driven by expectations that proximity to a village/town influenced food access. Eighteen sites were included; specific sites studied changed over time, as mines are regularly closing and being started.

The focus population was mothers of children under age 5 in mining households due to the importance of maternal and young child nutrition in development. Young single miners, primarily male, were also included to understand how experiences might vary across groups. Data were collected iteratively from May 2018 to December 2019. First, structured non-participant observations at ten mining sites were used to understand the setting, food availability, actors involved and work roles. Stakeholders (government, civil society and local ASM leaders) were consulted via key informant interviews. A cross-sectional household survey was carried out in two waves, with no overlap in respondents between waves. Households were chosen randomly, with sample size proportional to site population. Survey sample size was determined based on an ability to calculate the proportion of women with a minimally diverse diet, conservatively assuming a level of $50 \%$, alpha of 0.05 , power of 0.8 , beta of 0.2 and design effect of 1.5 , yielding a minimum sample size of 291 per wave. Households were eligible to participate if at least one member was active in mining and a child under 5 lived in the household. The mother/guardian of the youngest child was the primary respondent. In addition, two waves of in-depth interviews were conducted, covering mothers of young children, food vendors and young single miners. Twenty-five interviews with mothers also included extended periods of non-participant observation. Four market surveys were conducted, aiming to cover all major seasons. In each, 4-7 markets that served the mining sites targeted by the household survey were selected; the number of markets surveyed varied by wave, depending on how many sites had associated markets. In-depth non-participant observations were carried out at eight markets.

Data collection instruments were developed based on standard questions (e.g. from Demographic and Health Surveys) and validated tools used by other studies within the Drivers of Food Choice project portfolio, where relevant. Instruments were pilot-tested in a comparable community not targeted by the research and revised accordingly, primarily to shorten interview length. The survey and interview questionnaires were developed in French and translated orally into Malinké; an agreed-upon translation was developed and validated with interviewers during training. Household and market surveys used structured, mainly closed-ended questionnaires. Market surveys collected price and quantity data and covered all foods at least occasionally present in local markets aside from the 'basic ingredients and snacks' categories (see Table 5), wherein there was more diversity and indicative products were chosen to represent broader groups. Household survey questions on food acquisition measured the more frequently consumed foods (Table 6). Commercially processed drinks and snacks (e.g. cookies, candies, pasta and sardines), following a definition previously used for research in Guinea ${ }^{(67)}$, were also noted in observations. For the household and market observations, semistructured paper-based guides were used, including both categorical/closed-ended questions (e.g. distance to closest village) and open-ended ones (e.g. miners' working conditions).

Field research was conducted by up to nine data collectors, supervised by 2-5 supervisors (depending on the data collection wave). Data collectors were competitively selected from recent graduates of Université Julius Nyerere de Kankan's sociology department. All knew the local context well and were fluent in Malinké and French. Data collectors were trained in research ethics, interview methods and data-entry and note-taking methods in addition to the data-collection instruments. Each data 
collector specialised in either qualitative (in-depth interviews, observations) or quantitative (household and market survey) methods. Supervisors oversaw data collection progress and verified data quality daily.

Data from market and household surveys were entered via smartphones into a cloud-based data storage platform. Interview data were recorded via detailed interview notes and post-interview debriefings. During the non-participant observations, notes were taken on paper and later scanned/transcribed into electronic versions. All data were entered and analysed in French.

Interview notes were coded using deductive coding in ATLAS.ti ${ }^{(68)}$. An initial deductive coding scheme was created based on the thematic modules covered in the interview guides and applied to all collected data; similar codes were grouped into thematic categories (e.g. food preparation practices) and code summaries created. Quantitative data were cleaned and analysed using Stata SE15(69) via frequency tabulations and/or calculation of means. Dietary diversity was assessed via a list-based 24-h-recall using ten standard categories ${ }^{(70)}$. We also calculated the Household Food Insecurity Access Score ${ }^{(71)}$. For food price data, there was considerable variation across seasons and markets; as such, we calculated median price across all data points and the seasonal range in the across-market median price, to indicate seasonal price variability.

Table 1 summarises data collection methods, sample sizes and topics, while Table 2 indicates how these were used to measure different food environment dimensions, showing the diversity in evidence brought by the mix of methods used.

\section{Results}

\section{Sample overview and diets}

Table 3 presents the summary statistics from the survey respondents; they are also roughly representative of mothers included in in-depth interviews. Food vendors interviewed tended to be women ( $97.5 \%$ ) with children aged $20-55$ years. Single miners interviewed were predominantly male (93\%) aged $18-33$ years. Most vendors and single miners had migrated from elsewhere in the sub-national region.

Table 4 summarises women's diets, based on the household survey. Diets are largely inadequate from a nutritional perspective, with only a minority of women meeting the dietary diversity threshold ${ }^{(70)}$. Food groups that are particularly under consumed include egg, dairy, legumes, fruit and green leafy vegetables. Overall, $24.5 \%$ of households are moderately food insecure and $27.6 \%$ are severely food insecure $^{(71)}$.

\section{External food environment}

Key characteristics of the external food environment include food availability, prices, vendor properties and food properties ${ }^{(34)}$. Table 5 offers an overview of the foods available in open-air markets in the zones studied as well as median price and range in median price across seasons, based on market survey data. Basic ingredients (e.g. rice, onions, oil, sugar and salt) are available across all markets, as are some more nutritious foods (e.g. fish, egg). However, several types of vegetables, fruits and animal-source foods cannot be found in all markets. Moreover, prices are high

Table 1 Summary of methods

\begin{tabular}{|c|c|c|c|}
\hline Method & Target population & Sample size & Topics \\
\hline Household surveys & $\begin{array}{l}\text { Mothers or guardians of children } \\
\text { under the age of five in } \\
\text { households engaged in mining }\end{array}$ & $\begin{array}{c}613 \text { (in two waves of } \\
\sim 300, \text { August 2018, } \\
\text { March/April 2019) }\end{array}$ & $\begin{array}{l}\text { Demographics; income \& livelihoods; } \\
\text { diets; food insecurity; food access, } \\
\text { acquisition and preferences; household } \\
\text { decision-making }\end{array}$ \\
\hline \multirow[t]{3}{*}{$\begin{array}{l}\text { In-depth semi- } \\
\text { structured interviews }\end{array}$} & $\begin{array}{l}\text { Mothers of children under age five in } \\
\text { mining households }\end{array}$ & 45 (in two waves) & $\begin{array}{l}\text { Livelihoods; food access, acquisition, and } \\
\text { preferences; household decision-making } \\
\text { childcare }\end{array}$ \\
\hline & $\begin{array}{l}\text { Vendors (mobile \& fixed, including } \\
\text { small kiosks/shacks \& tables) of } \\
\text { food (meals, drinks, \& snacks) at } \\
\text { mining sites }\end{array}$ & 40 (in two waves) & $\begin{array}{l}\text { Livelihoods; food access, acquisition and } \\
\text { preferences; vendor decision-making }\end{array}$ \\
\hline & $\begin{array}{l}\text { Single miners (predominantly male, } \\
\text { one female) }\end{array}$ & 15 & $\begin{array}{l}\text { Livelihoods; food access, acquisition and } \\
\text { preferences; household decision-making }\end{array}$ \\
\hline $\begin{array}{l}\text { non-participant } \\
\text { observation }\end{array}$ & $\begin{array}{l}\text { Mothers of children under the age of } \\
\text { five in households engaged in } \\
\text { mining }\end{array}$ & 25 & $\begin{array}{l}\text { Food acquisition and preparation practices; } \\
\text { child feeding }\end{array}$ \\
\hline Market surveys & Public food markets & $\begin{array}{l}\text { 4-7 markets, at four } \\
\text { points in time ( } 23 \text { total } \\
\text { data points) }\end{array}$ & $\begin{array}{l}\text { Food availability, prices (assessed for the } \\
\text { most basic quality product for each } \\
\text { product; per kilogram where feasible and } \\
\text { using local units and a conversion factor } \\
\text { where not) }\end{array}$ \\
\hline Market observations & Public food markets & 8 & $\begin{array}{l}\text { Market organisational structure; physical } \\
\text { features; food presence }\end{array}$ \\
\hline
\end{tabular}


Table 2 Methods and main indicators used by food environment dimension

\begin{tabular}{|c|c|c|}
\hline $\begin{array}{l}\text { Food environment } \\
\text { dimension }\end{array}$ & Data collection methods & Main indicators/aspects \\
\hline \multicolumn{3}{|l|}{ External } \\
\hline Availability & $\begin{array}{l}\text { Market surveys (O); household survey (food } \\
\text { production \& sourcing, R) }\end{array}$ & $\begin{array}{l}\text { Presence of food source; presence of food category } \\
\text { or specific food }\end{array}$ \\
\hline Prices & Market surveys (O); vendor interviews (R) & $\begin{array}{l}\text { Median price; range in median prices; vendors' pricing } \\
\text { strategies }\end{array}$ \\
\hline $\begin{array}{l}\text { Vendor \& Product } \\
\text { properties }\end{array}$ & $\begin{array}{l}\text { Market/site observations (O); vendor and consumers } \\
\text { interview }(P, R)\end{array}$ & $\begin{array}{l}\text { Vendor demographics; type of vendor (i.e. kiosk, open } \\
\text { table); market days; food category or specific food } \\
\text { sold; perceptions of food quality and safety }\end{array}$ \\
\hline Marketing* & $\begin{array}{l}\text { Market/site observations }(O) \text {; in-depth interview } \\
\text { vendors }(P)\end{array}$ & Presence of advertising; use of promotions \\
\hline \multicolumn{3}{|c|}{ 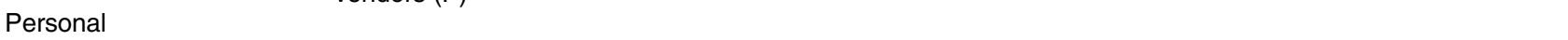 } \\
\hline Accessibility & $\begin{array}{l}\text { Household survey questions (food production \& } \\
\text { sourcing, food store access, P/R); consumers } \\
\text { interviews (perceptions of accessibility, P) }\end{array}$ & $\begin{array}{l}\text { Walking time to food sources; share of food sourced } \\
\text { from different sources (including own production); } \\
\text { qualitative perceptions of accessibility }\end{array}$ \\
\hline Affordability & $\begin{array}{l}\text { Household survey (income, R); consumers interviews } \\
\text { (perceptions of relative food affordability, purchasing } \\
\text { choices in response to questions about using a } \\
\text { hypothetical budget, P) }\end{array}$ & $\begin{array}{l}\text { Self-reported income for an 'average' and 'good' } \\
\text { week; perceptions of relative food affordability; } \\
\text { change in stated purchasing choices as } \\
\text { hypothetical budget varied }\end{array}$ \\
\hline Convenience & $\begin{array}{l}\text { Household survey (rating question on key criteria } \\
\text { when choosing food, } P \text { ); vendor and consumer } \\
\text { interviews }(P) \text {; observations (of time use, } O \text { ) }\end{array}$ & $\begin{array}{l}\text { Importance of convenience-related attributes; vendors' } \\
\text { perceptions of consumers' convenience } \\
\text { preferences; consumers' perceptions of } \\
\text { convenience; time use related to preparing food } \\
\text { and eating }\end{array}$ \\
\hline Desirability & $\begin{array}{l}\text { Household survey (rating question on key criteria } \\
\text { when choosing food, } P \text { ); vendor and consumer } \\
\text { interviews }(P)\end{array}$ & $\begin{array}{l}\text { Importance of desirability-related attributes; vendors' } \\
\text { perceptions of consumers' desirability preferences; } \\
\text { consumers' perceptions of desirability; respondents' } \\
\text { general views on food culture and habits }\end{array}$ \\
\hline
\end{tabular}

Dimensions are classified as per ${ }^{(39)}$. To clarify the type of evidence presented on each food environment dimension, we note whether data are objective (via direct observation) (O); objective fact as reported by participants $(\mathrm{R})$ or participants' personal perceptions $(\mathrm{P})$.

*Initial key informant interviews indicated that regulation was essentially absent from the sites, which was confirmed via initial observations. As such, regulation was not examined in depth.

for a number of nutritious options (e.g. beef, chicken) and relatively higher for more nutrient-dense options compared with alternatives (e.g. white rice or maize flour is cheaper than the protein-rich local grain fonio, beans or cowpeas). There is widespread availability of commercially processed, packaged products (e.g. pasta, sardines, cookies and candies). Particularly striking is the number of energy drinks (local or off-brand versions of Red Bull) on offer. Comparing availability and prices across markets associated with different site types (data not shown) suggests that remote mining camps have both the lowest availability and highest prices for many foods. Lower availability was confirmed by an eight-market case study associated with this study ${ }^{(72)}$. Most miners and food vendors opined in interviews that prices at mining sites were often higher than in towns.

Qualitative interview responses offered insights into how ASM impacts food availability. For example, a 21-year-old female miner noted, 'It's hard to find food to eat here, but in town, it's easy; the difference is that here the vendors don't give enough food ... in town, all types of food are available...' One vendor stated bluntly, 'The clients (at the mining site) are required to buy what they find from us, even if the price is expensive' (45-year-old female). Some vendors also mine, which further steers them to offering easy, convenient foods: 'I sell (commercially processed foods) because they don't take much care to maintain, that gives me time to go mine myself, then come back and sell them' (male snack vendor, age unknown).

Observations showed that available food outlets in villages serving mining sites include open-air markets (daily or weekly) and small shops/kiosks selling mainly packaged foods as well as basic prepared foods (e.g. omelets). Mining sites themselves have few unprepared foods or ingredients for sale but host numerous mobile vendors of prepared foods as well as basic cafes. Survey data indicate that, from their home, $88 \%$ of respondents have a prepared food vendor within a 15 -minute walk, whereas only $48 \%$ have access to a large store and $60 \%$ to an open-air market (which may not be open daily). Food vendors are generally women and come from other areas; interview responses suggested most to be attracted by the lucrative opportunity offered by mining sites: 'I don't know anything about mining,' one vendor noted, 'I just come here to sell (my food) ... I just sell food because that's where I have luck, that's where I earn money' (34-year-old female).

Many vendors explained that they integrate preparation of food to sell into cooking for their families. Some sell from a bowl on the ground; others set up temporary stalls with tables. They mainly offer cooked meals aligning to local recipes (e.g. rice with sauce); some also offer drinks (e.g. water in small bags). Service is fast, and they locate 
Table 3 Characteristics of survey respondents

\begin{tabular}{|c|c|c|}
\hline & Frequency & Percent \\
\hline \multicolumn{3}{|l|}{ Respondent characteristics ( $n$ 613) } \\
\hline \multicolumn{3}{|l|}{ Age } \\
\hline Mean & \multicolumn{2}{|c|}{$26 \cdot 1$} \\
\hline SD & \multicolumn{2}{|c|}{$6 \cdot 6$} \\
\hline Married (monogamous) & 386 & $46.7 \%$ \\
\hline Married (polygamous) & 312 & $50.9 \%$ \\
\hline Illiterate & 555 & $90.5 \%$ \\
\hline Fully literate & 35 & $5.7 \%$ \\
\hline Received any education & 108 & $17.6 \%$ \\
\hline Finished primary school & 64 & $10.4 \%$ \\
\hline $\begin{array}{l}\text { Originally from village/town(s) associated } \\
\text { with mine }\end{array}$ & 241 & $39.3 \%$ \\
\hline Non-Guinean & 6 & $1.0 \%$ \\
\hline \multicolumn{3}{|l|}{ Main economic activity } \\
\hline Mining & 478 & $78.0 \%$ \\
\hline Food selling & 42 & $6.9 \%$ \\
\hline Other & 93 & $15.2 \%$ \\
\hline Seasonal inhabitant & 115 & $18 \cdot 8 \%$ \\
\hline Muslim & 596 & $97.6 \%$ \\
\hline Malinké speaking & 575 & $94.1 \%$ \\
\hline \multicolumn{3}{|l|}{ Household characteristics } \\
\hline \multicolumn{3}{|l|}{ Household size } \\
\hline Mean & \multirow{2}{*}{\multicolumn{2}{|c|}{$\begin{array}{l}8 \cdot 1 \\
6 \cdot 24\end{array}$}} \\
\hline SD & & \\
\hline \multicolumn{3}{|l|}{$\begin{array}{l}\text { Number of children aged under } 5 \text { years } \\
\text { in household }\end{array}$} \\
\hline Mean & \multicolumn{2}{|l|}{$2 \cdot 5$} \\
\hline SD & \multicolumn{2}{|l|}{$2 \cdot 7$} \\
\hline \multicolumn{3}{|l|}{$\begin{array}{l}\text { Number of children aged 5-15 years } \\
\text { in household }\end{array}$} \\
\hline Mean & \multicolumn{2}{|l|}{$2 \cdot 1$} \\
\hline SD & \multicolumn{2}{|l|}{$1 \cdot 2$} \\
\hline Improved toilet & 172 & $28.1 \%$ \\
\hline Improved water source & 293 & $48.0 \%$ \\
\hline \multicolumn{3}{|l|}{ Food access from own production } \\
\hline Cultivated agricultural land in past 2 years & 366 & $59.9 \%$ \\
\hline Has a food garden & 99 & $16 \cdot 2 \%$ \\
\hline Owns chickens & 288 & $47.1 \%$ \\
\hline Owns other livestock & 235 & $38.5 \%$ \\
\hline
\end{tabular}

themselves close to mine shafts to allow miners to minimise time spent not working. Cafes are more likely to be run by men and offer commercially processed drinks (e.g. instant coffee and energy drinks) and basic foods (e.g. omelets and sandwiches).

Observations and interviews showed that foods on sale at sites include traditional dishes aligning to local preferences as well as commercially processed foods once only available in cities. All foods are ready-to-eat and available quickly; most are either cheap (e.g. individually sold candies) or sold in a range of sizes at different prices. For example, the price of a plate of rice depends on the portion size and how many meat pieces are included. While nutritious options exist, observations and interviews suggest the lowest-priced meal options are heavily dependent on staple grains (e.g. rice with a bit of thin sauce). Most snack options are high on refined sugars and low on micronutrients or protein (e.g. packaged cookies). All commercially processed foods and some homemade ones come in plastic packaging for protection from the mine's dust. However, several interviewees
Table 4 Women's dietary diversity and consumption of major food groups

\begin{tabular}{lrr}
\hline & Frequency & Percent \\
\hline Women's dietary diversity score* & \multicolumn{2}{c}{3.3} \\
Mean & \multicolumn{2}{c}{1.67} \\
SD & 140 & $22.8 \%$ \\
Percent meeting minimum dietary diversity & \multicolumn{2}{c}{} \\
$\quad$ (5 of 10 groups) & \multicolumn{2}{c}{} \\
Percent consuming in prior $24 \mathrm{~h} .$. & 588 & $96.2 \%$ \\
Starches and grains & 155 & $25.4 \%$ \\
Dark green leafy vegetables & 250 & $40.9 \%$ \\
Other vitamin-A rich fruit and vegetables & 304 & $49.8 \%$ \\
Other vegetables & 54 & $8.8 \%$ \\
Other fruit & 64 & $10.5 \%$ \\
Egg & 186 & $30.4 \%$ \\
Meat & 339 & $55.5 \%$ \\
Fish or shellfish & 89 & $14.6 \%$ \\
Legumes & 87 & $14.2 \%$ \\
Dairy & 147 & $24.0 \%$ \\
Sweets & 90 & $14.7 \%$ \\
Energy drinks $\dagger$ & \multicolumn{2}{c}{611} \\
n. & \multicolumn{2}{l}{}
\end{tabular}

*Due to a survey error, the 'pulses' and 'nuts/seeds' groups of the standard 'Minimum Dietary Diversity-Women' (MMD-W) score were not separated for the first wave of the survey (approximately half of responses). The 'pulses/nuts/ seeds' group formed by combining 'pulses' and 'nuts/seeds' using wave 2 data was reported as consumed significantly more often than the combined group in wave 1 , implying that MDD-W was underestimated in wave 1 data.

tWhile not a standard category, energy drinks were included due to initial observations and key informants indicating these as widely consumed.

mentioned that poor-quality (e.g. spoiled, expired, or damaged) food was commonly sold. As one food vendor noted, 'While some (commercially processed foods) exist in Conakry, too... the food quality...that exists in Conakry does not exist here' (52-year-old female). Poor quality and limited availability were attributed to poor infrastructure, including poor-quality roads and little electricity or running water.

We found that sites typically hosted many food vendors, who are largely similar in terms of food offerings and prices. However, interviews with customers and vendors indicated several characteristics that vendors use to distinguish themselves and attract customers. These include hygiene and food safety (i.e. having a clean table and clothes) and offering credit. In the words of one male snack vendor (age unknown), 'To make sure that clients come back to me, I don't make them pay in cash for the food they want if they don't have money on them. Some people never forget those who help them in difficult times.' Many interviewed miners confirmed choosing vendors based on ability to buy on credit.

Advertising and promotions for specific brands (e.g. posters, painted walls, billboards and shelf displays) are almost entirely absent from these markets, aside from branded labels on commercially processed foods. However, individual vendors confirmed that they offered incentives, such as gifts (e.g. free water), to attract or retain clients in the competitive market. Market observations showed some vendors using megaphones or speakers to advertise items. 
Table 5 Availability and prices of foods in open-air markets*, $\dagger$

\begin{tabular}{|c|c|c|c|c|c|c|c|c|c|}
\hline & $\begin{array}{c}\text { Avg. Pct of } \\
\text { Markets Selling }\end{array}$ & $\begin{array}{c}\text { Median } \\
\text { Price (GNF) }\end{array}$ & IQR (GNF) & $\begin{array}{l}\text { Seasonal range in } \\
\text { median price (GNF) }\end{array}$ & & $\begin{array}{l}\text { Avg. Pct of } \\
\text { Markets Selling }\end{array}$ & $\begin{array}{c}\text { Median } \\
\text { Price (GNF) }\end{array}$ & IQR (GNF) & $\begin{array}{l}\text { Seasonal range in } \\
\text { median price (GNF) }\end{array}$ \\
\hline \multicolumn{5}{|c|}{ Grains \& Staples } & \multicolumn{5}{|c|}{ Legumes } \\
\hline Maize flour & $85 \%$ & 5000 & $2000-7666$ & $5000-7000$ & Cowpea & $35 \%$ & 7000 & $6500-7500$ & $7000-10000$ \\
\hline Maize kernels & $74 \%$ & 5000 & $2500-6000$ & $3750-5000$ & Bean & $75 \%$ & 8500 & $8000-10000$ & $7000-10000$ \\
\hline Rice & $100 \%$ & 6500 & $6000-7000$ & $6500-6800$ & Animal-source foods & & & & \\
\hline Millet & $19 \%$ & 6000 & $6000-10000$ & $6000-10000$ & Fresh fish & $100 \%$ & 25000 & $20000-25000$ & 22 500-25000 \\
\hline Sorghum & $50 \%$ & 7000 & $6250-7000$ & $6000-7000$ & Dried fish & $92 \%$ & 27000 & $20000-40000$ & $27000-65000$ \\
\hline Fonio & $88 \%$ & 10000 & $9000-10000$ & $9500-10000$ & Sardines (1 tin) & $96 \%$ & 5000 & $5000-5000$ & 2. \\
\hline Wheat flour & $57 \%$ & 7000 & $7000-7000$ & $7000-7000$ & Beef & $92 \%$ & 30000 & $30000-30000$ & $30000-31250$ \\
\hline Pasta/Noodles & $100 \%$ & 5000 & $5000-7000$ & $3500-11000$ & Local chicken (1 bird) & $57 \%$ & 47500 & $40000-81666$ & $40000-66250$ \\
\hline Bread (1 baguette) & $100 \%$ & 2000 & $2000-2000$ & $2000-2000$ & Imported chicken ( 1 bird) & $96 \%$ & 25000 & $20000-25000$ & $20000-25000$ \\
\hline Cassava & $33 \%$ & 3500 & $2000-5000$ & $2500-5000$ & $\operatorname{Egg}(1)$ & $100 \%$ & 1500 & $1500-1875$ & $1500-2000$ \\
\hline $\begin{array}{l}\text { Plantain } \\
\text { Plain }\end{array}$ & $52 \%$ & 10000 & $10000-11000$ & $8000-11500$ & Lait caillé ( 1 I.) & $60 \%$ & 11000 & $10000-15000$ & $8000-13000$ \\
\hline White Sweet Potato & $59 \%$ & 5000 & $5000-10000$ & 3333-10 000 & Powdered milk (20 g packet) & $100 \%$ & 1000 & $1000-1000$ & - \\
\hline Orange Sweet Potato & $36 \%$ & 1750 & $1000-2000$ & $1000-2000$ & Basic ingredients & & & & \\
\hline $\begin{array}{l}\text { Potato } \\
\text { Pand }\end{array}$ & $80 \%$ & 10000 & $10000-12500$ & $8000-12500$ & Oil (1 I.) & $100 \%$ & 13750 & $12750-15000$ & $13000-14500$ \\
\hline Vegetables & & & & & Red palm oil (1 l I.) & $100 \%$ & 11000 & $10000-12000$ & $11000-12000$ \\
\hline Onion & $100 \%$ & 10000 & $8750-12000$ & $7000-11500$ & Sugar $(100 \mathrm{~g})$ & $100 \%$ & 1000 & $900-1000$ & $800-1000$ \\
\hline Tomato & $76 \%$ & 1750 & $1000-3000$ & $2000-4500$ & Snacks & & & & \\
\hline Dark leafy greens & $89 \%$ & 1250 & $500-2000$ & $1500-4583$ & Peanuts (small bag) & $88 \%$ & 800 & $500-1000$ & $500-950$ \\
\hline Eggplant & $100 \%$ & 1750 & $1000-3500$ & $2000-8333$ & Fizzy drink ( 1 small bottle) & $100 \%$ & 6500 & $6000-7000$ & $6000-7000$ \\
\hline African Eggplant & $100 \%$ & 1000 & $1000-1500$ & $1000-6071$ & $\begin{array}{l}\text { Homemade juice (1 small } \\
\text { bottle) }\end{array}$ & $94 \%$ & 2000 & $1500-2000$ & $1000-2000$ \\
\hline Lettuce & $44 \%$ & 5000 & $3000-5000$ & $5000-9167$ & Beignets (1) & $75 \%$ & 750 & $500-1000$ & $750-1000$ \\
\hline Cucumber & $31 \%$ & 2125 & $1250-3000$ & $2125-3000$ & Cake/cupcake (1) & $83 \%$ & 500 & $500-1000$ & $500-750$ \\
\hline Fruits & & & & & Cookies (homemade) (1 pack) & $49 \%$ & 1000 & $500-1000$ & $5000-1000$ \\
\hline Banana $(1$, medium $)$ & $80 \%$ & 1000 & $1000-1670$ & $813-1666$ & Cookies (commercial) (1 pack) & $100 \%$ & 1000 & $1000-3000$ & $1000-5000$ \\
\hline Mango ( 1 , medium) & $25 \%$ & 2000 & $1000-2750$ & $1875-2000$ & Candies (1) & $100 \%$ & 500 & $500-500$ & $500-500$ \\
\hline Avocado ( 1 , medium) & $38 \%$ & 3500 & $2250-5000$ & $2500-5000$ & & & & & \\
\hline Orange $(1$, medium $)$ & $69 \%$ & 1000 & $500-1000$ & $500-1350$ & & & & & \\
\hline
\end{tabular}

Avg, average.

*Data are from December 2018 and March, July and December 2019. Price is per kilogram

tData are from December 2018 and March, July and December 2019. Medians are reported rather than means due to the presence of outliers in the data. The column 'seasonal range in median price' presents the range across seasons of the median price across markets (i.e. one median price was calculated for each of December 2018, March, July and December 2019, and the range in those four median prices is shown here). Price is per kilogram unless otherwise specified, in Guinean Franc (GNF). Over this time period, the GNF was relatively stable, at 9100-9500 GNF to 1 USD. Unavailable foods (mutton and goat meat) are not included; data for yam and salt are excluded due to inconsistent units across surveys. 


\section{Personal food environment}

Only $16.2 \%$ of mining households have access to food from gardens, $59.9 \%$ from agricultural production (within the prior two years), $47 \%$ from poultry and $38.5 \%$ from other livestock; $25 \%$ have no access to food from own production (see Table 3). For those who do, production is fairly minor: only $2.5 \%$ of respondents see agriculture as a main economic activity. This varies by site type, with those in temporary camps least likely to have access to food from own production and those in villages most likely to (e.g. $6.6 \%$ of those in camps had farmed in the prior two years, $v .63 .7 \%$ in villages near towns); this trend aligns to variations in food availability in open-air markets. Table 6 summarises sources for main staples and key nutrient-dense foods from survey data, showing what percentage of households obtain half or more of each food from home production and confirming that households obtain limited food from own production and are largely

Table 6 Main foods consumed and consumption from home production*

\begin{tabular}{|c|c|c|c|}
\hline & \multicolumn{3}{|c|}{ Percentage of households ( $n$ 303) } \\
\hline & $\begin{array}{l}\text { Consuming } \\
\text { never or } \\
\text { rarely }\end{array}$ & $\begin{array}{l}\text { Consuming } \\
\text { every day } \\
\text { or nearly } \\
\text { everyday }\end{array}$ & $\begin{array}{l}\text { Obtaining half or } \\
\text { more of their } \\
\text { consumption from } \\
\text { own production }\end{array}$ \\
\hline & $\%$ & $\%$ & $\%$ \\
\hline \multicolumn{4}{|l|}{ Grains and staples } \\
\hline Rice & $3 \cdot 0$ & $96 \cdot 0$ & $42 \cdot 2$ \\
\hline Bread & 11.6 & $62 \cdot 0$ & 5.5 \\
\hline Maize & $42 \cdot 2$ & $27 \cdot 7$ & 41.4 \\
\hline Cassava & $54 \cdot 5$ & 14.9 & $16 \cdot 8$ \\
\hline Pasta & $56 \cdot 4$ & $12 \cdot 0$ & $2 \cdot 0$ \\
\hline Sweet potato & 58.4 & $9 \cdot 6$ & $12 \cdot 6$ \\
\hline \multicolumn{4}{|l|}{ Vegetables } \\
\hline Onion & $5 \cdot 0$ & $91 \cdot 1$ & $15 \cdot 6$ \\
\hline $\begin{array}{l}\text { Dark-green leafy } \\
\text { vegetables }\end{array}$ & $40 \cdot 9$ & $21 \cdot 5$ & $11 \cdot 2$ \\
\hline Eggplant & $21 \cdot 1$ & $53 \cdot 1$ & $10 \cdot 6$ \\
\hline Tomato & 39.9 & $24 \cdot 8$ & $9 \cdot 4$ \\
\hline Cabbage/lettuce & $68 \cdot 0$ & $11 \cdot 6$ & 2.5 \\
\hline Carrot & $92 \cdot 7$ & 0.0 & $4 \cdot 6$ \\
\hline Other vegetables & $47 \cdot 9$ & $23 \cdot 1$ & $18 \cdot 4$ \\
\hline \multicolumn{4}{|l|}{ Fruits } \\
\hline Mango & 63.7 & $5 \cdot 9$ & $33 \cdot 3$ \\
\hline Papaya & $89 \cdot 8$ & 1.0 & $10 \cdot 9$ \\
\hline Other fruit & $61 \cdot 7$ & $5 \cdot 3$ & $6 \cdot 6$ \\
\hline \multicolumn{4}{|l|}{ Animal-source foods } \\
\hline Fresh fish & $21 \cdot 0$ & $64 \cdot 7$ & 2.5 \\
\hline Dried fish & $54 \cdot 8$ & $21 \cdot 5$ & 0.9 \\
\hline Dairy products & $47 \cdot 5$ & $18 \cdot 8$ & $5 \cdot 3$ \\
\hline Egg & $42 \cdot 2$ & $15 \cdot 2$ & $2 \cdot 0$ \\
\hline Poultry & $42 \cdot 2$ & 11.9 & $4 \cdot 2$ \\
\hline Meat & $32 \cdot 7$ & $11 \cdot 6$ & $3 \cdot 2$ \\
\hline \multicolumn{4}{|c|}{ Nuts, seeds and legumes } \\
\hline Peanut & $16 \cdot 2$ & 55.4 & $24 \cdot 3$ \\
\hline Beans/cowpea & $58 \cdot 1$ & $11 \cdot 2$ & $7 \cdot 3$ \\
\hline $\begin{array}{l}\text { Lentils, nuts and } \\
\text { seeds }\end{array}$ & $92 \cdot 7$ & 0.7 & $3 \cdot 3$ \\
\hline
\end{tabular}

*The sample size is 303 as these questions were asked in only wave 1 , not both survey rounds. Within each food group, foods are sorted based on percentage of households consuming every day or nearly every day. dependent on markets. Water access is also limited among the sample, with slightly less than half having access to an improved water source. Nearly all households use informal open-air kitchens as their cooking facilities, with wood or charcoal as fuel.

Understanding affordability requires relating prices to purchasing power. Interviews indicated that elevated prices exist alongside (somewhat) elevated incomes: 'One earns money easily here,' one 20-year-old female vendor explained, 'but one spends it easily, too, due to the high prices.' As explored in more detail elsewhere ${ }^{(73)}$, ASM miners are dependent on highly variable incomes, which depend on how much gold they find. Put simply, 'if you find enough gold, you eat well' (25-year-old single male miner). Indeed, qualitative data show considerable variation in food choice depending on daily income. One in-depth interview question asked respondents what food they would purchase on a hypothetical day when they made a given amount of money (the median reported revenue), then what they would buy if they had $50 \%$ more or $50 \%$ less. In general, increased income resulted in adding (or increasing) fish, meat or chicken; shifting from fish to meat; adding vegetables; increasing the amount of oil and having more sauce for a given amount of rice. A decrease resulted in no fish (or meat), less rice, no or different vegetables and using red palm oil instead of commercially processed vegetable oil. Affordability is clearly a key, but variable, constraint on food choices; participants' responses suggested it was the main reason why certain foods are widely available but not commonly consumed (e.g. egg, meat, dairy). From the vendor perspective, affordability is essential for remaining competitive: 'I set my prices so that (the miners) buy my food quickly, because if it is cheaper, you'll have lots of clients,' explained one 55-year-old female food vendor.

In addition to affordability, convenience is an important attribute of the personal food environment. At the site itself, interviewees opined that convenience manifests primarily in vendor location (i.e. their proximity to the mining shaft). 'When I want something (to eat while mining), explained an 18-year-old single male miner, 'I just go to whatever cafe is closest.' Time places an additional constraint on food access and further emphasises convenience, as miners are working at the site from early morning until late afternoon. These schedules can lead to changes in mealtimes (e.g. about $20 \%$ of respondents reported eating the morning meal earlier than normal and/or the evening meal later) or meal skipping. Given local gender norms, men who live without a female relative are largely dependent on food vendors for meals.

Considering desirability, taste, clean or hygienic preparation, family preferences, healthiness and price were cited by survey respondents as the most important characteristics sought in food, whereas it was seen as least important for food to be novel, modern or have attractive packaging. There were, however, some who saw packaging as a mark 
of food quality or cleanliness. Vendors share similar views on client preferences. 'My only strategy for attracting clients,' stated one 38-year-old female mobile snack vendor, 'is to make my cakes delicious. People like what is delicious.' Interviews also indicated that mining directly influences food preferences through a preference for foods and drinks seen to give energy - such as instant coffee or canned energy drinks: 'Here is a mine,' one 30-year-old male café operator explained, 'so even before eating (whatever they eat), the miners will have a black coffee.'

The survey data ranking food characteristics suggested 'health' was an important factor in food choice; while this might be assumed to refer to nutritional content, qualitative interviews suggest that understanding of nutrition is very limited. Indeed, many see 'healthy' food as being the same as 'safe or hygienic food'; when asked to cite healthy foods, a greater percentage named juice drinks or soft drinks (29\%) than named fruit (19\%) or vegetables (17\%).

\section{Discussion}

Using diverse methods, this paper has analysed the personal and external food environments of artisanal mining communities in Guinea. Figure 1 summarises the key characteristics uncovered.

From examining this figure, it is clear that this rural setting has many characteristics typically associated with urban areas. Packaged and prepared foods are widely available, including commercially processed drinks and snacks. Consumers are largely dependent on cash incomes, with limited access to food from own production. They place a premium on convenience and rapidly accessible food. However, they also have some agricultural production and limited access to options for purchasing nonprepared foods (e.g. no supermarkets, in some cases, no daily open-air market), refrigeration and cooking technology and complementary services (e.g. piped water) and have physically demanding livelihoods dependent on natural resources. These communities' food environments thus mix characteristics traditionally associated with rural or urban populations ${ }^{(24)}$. While these sites are unusual, their characteristics are by no means unique. Even in rural areas of sub-Saharan Africa, households purchase much of their food ${ }^{(18,19)}$. Consumption of commercially processed foods is fairly common in rural areas - even in West Africa, even by young children ${ }^{(74)}$. This complexity underlines the importance of further interrogating food environments across diverse LMIC settings, including rural areas.

Food environments alone do not determine food choices, and research in high-income settings has suggested personal perceptions may be stronger determinants than environmental characteristics, such as prices and availability $^{(75)}$. However, there are some clear ways in which these environments' characteristics may influence diets and nutrition. Limited access to own-produced foods, along with low, variable cash incomes, creates a situation that fosters food insecurity and diets low in diversity despite widespread availability of nutrient-dense foods, such as meat and eggs, in many markets. This disconnect between food availability and food/nutrition security emphasises the need for more research on food affordability in LMIC $^{(67,76-78)}$ : availability means little when not accompanied by affordability. However, the literature generally considers food affordability to be a largely static concept, comparing food prices to average annual/monthly

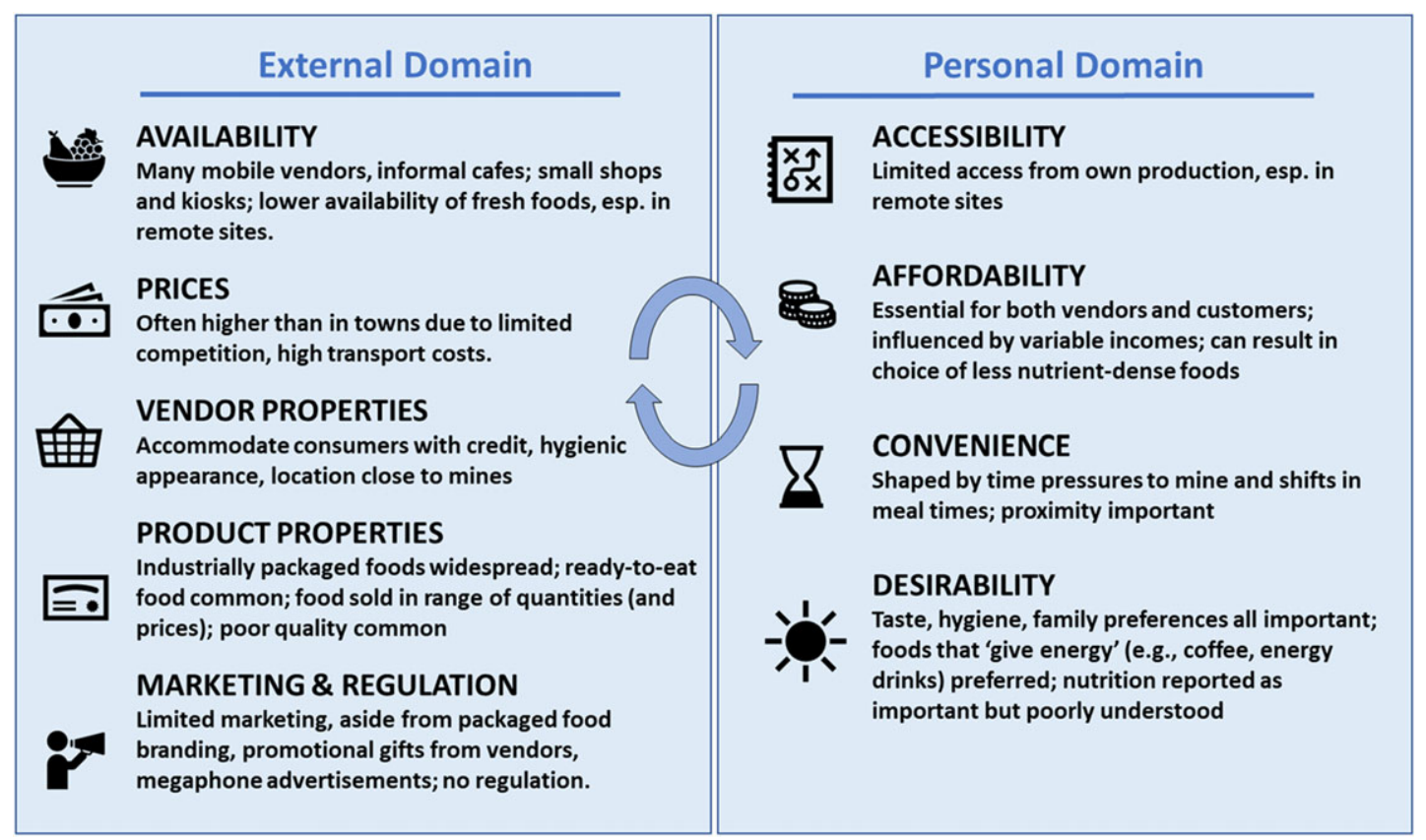

Fig. 1 Summary of Main Results, by Food Environment Characteristic 
incomes or expenditures, without considering the substantial income variability that affects the miners studied here and many other informal workers. For affordability metrics to give an accurate picture of the constraints consumers face, income variability must be given more primacy. In this setting, income variability is likely to be an even more important driver for women, as their roles in mining (hauling and washing) are less lucrative than those of men (digging and operating machines $)^{(73)}$, underlining how the personal food environment may vary by socio-demographic group.

This study also uncovered easy availability of affordable, convenient and nutrient-poor commercially processed foods. This availability arises at mining sites due to vendors recognising potential demand, which intersects with miners' desire to have more energy to mine and to consume 'clean' foods with lower risk of contamination in an unclean environment. Jointly, these factors lead to surprisingly frequent consumption of commercially processed sweets and energy drinks, including by young children. Such consumption (especially in a setting of overall food insecurity) by young children could lead to nutrient displacement ${ }^{(79)}$; in adults, the consumption of ultra-processed foods (a subcategory of commercially processed foods) has been connected with obesity and non-communicable diseases ${ }^{(80,81)}$. However, their consumption is rarely seen as a major issue in rural areas of lower-income countries, on the understanding that such areas have not yet 'transitioned' to modern food systems ${ }^{(17)}$. This study underlines the importance of broadening that lens and considering availability of commercially processed foods in rural food environments.

In the more remote camps, moreover, the availability of affordable, fresh, nutritious products was particularly low. Food diversity in rural markets has been shown to influence children's dietary diversity ${ }^{(21)}$; this is likely even more true in mining camps, where there are few options for home food production. Indeed, many dietary indicators were found to be poorest in the more remote mining camps.

The results presented here also show how food environments are dynamic and emerge from an interaction of suppliers and consumers amid larger contextual forces. In this setting, the widespread availability of ready-made and commercially processed food, as well as limited access to food from own production, is by-products of the predominant local livelihood. As compared with an agricultural livelihood, ASM offers the potential for greater incomes ${ }^{(26,27)}$ but also more day-to-day variability in income $^{(73)}$. While ASM can complement agriculture ${ }^{(26,51,82-85)}$, it tends to reduce reliance on farming; for migrants, it can mean limited access to livestock or land to produce crops. ASM is a high-pressure, competitive and time-consuming occupation, leading miners to place greater weight on convenience and to seek foods they hope will give them energy. Prepared food vendors, once rare in such rural settings, emerge to cater to these needs. In response to customer demand, they offer prepared meals and energy drinks within steps of mine shafts.
Their focus on hygiene (amid an unclean environment) and offering dishes at a range of prices and on credit (when facing clients with irregular income) further demonstrate the ways in which they respond to customers' needs. The resultant food environment is thus a product of supply and demand interacting within a given context and a larger food system.

There are numerous limitations of this study. Mine locations change often, and there are challenges with accessing them. Different villages and markets were thus sampled for different parts of data collection, and it was not possible to create a truly random or population-representative sample. Data were collected only in mining areas and only over an 18-month period, making it impossible to compare trends over time or to non-mining areas. The study's strengths include an in-depth, comprehensive approach that used diverse methods over an extended period of time. The result is a detailed picture of the personal and external food environments within a rural, non-agricultural LMIC setting.

The results have implications for policy and programming to improve nutrition in similar areas. In this setting, food availability is not a major barrier to consumption, whereas affordability is largely due to highly variable incomes. As such, efforts could be made to stabilise incomes (e.g. through savings groups or mobile banking). Formalisation of property rights could also have a positive effect, as it stabilises income from mining and allows for more advance budgeting and planning ${ }^{(86)}$. Encouraging agriculture to improve food accessibility is unlikely to be attractive to those engaged in mining, given the appeal of earning a fast cash income and the time-demanding nature of mining. However, time-efficient, low-labour options for food production, such as keyhole gardens or chicken-rearing, could be tested. Vendors could be supported with training to offer more nutrient-dense options and fewer ultra-processed foods - such as by greater use of relatively affordable nutrient-dense foods (e.g. organ meats, dried fish). To reshape food desirability, messaging could work to counteract miners' common belief that nutrient-poor ultra-processed foods/beverages (e.g. energy drinks) are good sources of energy for mining. Finally, while government regulation of food quality and safety at sites is effectively non-existent and infeasible to expect in the short term, given limited resources, site infrastructure could be improved to support food safety. When translated into such tailored intervention approaches, greater attention to non-agricultural rural food environments in research and policy could help reduce malnutrition among some of Africa's most vulnerable communities.

\section{Acknowledgements}

Acknowledgements: The authors would like to acknowledge our field interviewers from Julius Nyerere University of Kankan for conducting and translating interviews as well 
as Helen Keller International Guinea staff for field support, Fatima Koroma for assistance in data collection, Amy Nye for assistance in data analysis and Hannah Marker for assistance in planning the study. We also thank two anonymous reviewers and the editors for their helpful feedback. The contents of this paper are the sole responsibility of the authors and do not necessarily reflect the views of GAIN. Financial support: This work was supported by the Drivers of Food Choice Competitive Grants Program, funded by the UK government's Department for International Development and the Bill \& Melinda Gates Foundation and managed by the Arnold School of Public Health, University of South Carolina. The views expressed do not necessarily reflect the UK Government's official policies. Conflicts of interest: There are no conflicts of interest. Authorship: S.N., R.D.K. and P.J.W. formulated the research question(s) and study design, with input from M.L.F.; M.L.F., A.O.B., S.D., J.L.S., R.S.W. and L.X.Z. contributed to design and undertook/supervised data collection; S.N., R.S.W. and L.X.Z. analysed the data; S.N. led drafting of the manuscript; all authors approved the manuscript before submission. Ethics of buman subject participation: This study was conducted according to the guidelines laid down in the Declaration of Helsinki, and all procedures involving research study participants were approved by Guinea's national research ethics council (Comité National d'Ethique et de Recherche en Santé, number 080/CNERS/18). Written informed consent was obtained from all subjects.

\section{References}

1. Furst T, Connors M, Bisogni CA et al. (1996) Food choice: a conceptual model of the process. Appetite 26, 247-266.

2. Sobal J \& Bisogni CA (2009) Constructing food choice decisions. Ann Behav Med 38, s37-s46.

3. Leigh Gibson E (2006) Emotional influences on food choice: sensory, physiological and psychological pathways. Mak Sense Food 89, 53-61.

4. HLPE (2017) Nutrition and Food Systems. Rome: High Level Panel of Experts on Food Security and Nutrition (HLPE), Committee on World Food Security. http://www.fao.org/3/ i7846e/i7846e.pdf (accessed April 2020).

5. GloPan (2017) Improving Nutrition Through Enhanced Food Environments. London: Global Panel on Agriculture and Food Systems for Nutrition (GloPan). https://glopan. org/sites/default/files/FoodEnvironmentsBrief.pdf (accessed April 2020).

6. Turner C, Kalamatianou S, Drewnowski A et al. (2019) Food environment research in low- and middle-income countries: a systematic scoping review. Adv Nutr 11, 387-397.

7. Development Initiatives (2018) 2018 Global Nutrition Report: Shining a Light to Spur Action on Nutrition. Bristol: Development Initiatives.

8. Afshin A, Sur PJ, Fay KA et al. (2019) Health effects of dietary risks in 195 countries, 1990-2017: a systematic analysis for the Global Burden of Disease Study 2017. Lancet 393, 1958-1972.

9. Anggraini R, Februhartanty J, Bardosono S et al. (2016) Food store choice among urban slum women is associated with consumption of energy-dense food. Asia Pac J Public Health 28, 458-468.
10. Dake FAA, Thompson AL, Ng SW et al. (2016) The local food environment and body mass index among the Urban Poor in Accra, Ghana. J Urban Health Bull NY Acad Med 93, 438-455.

11. Barr S (2017) Using mixed methods to describe a spatially dynamic food environment in Rural Dominican Republic. Hum Ecol 45, 845-851.

12. Wust N, Rauscher-Gabernig E, Steinwider J et al. (2017) Risk assessment of dietary exposure to tryptamine for the Austrian population. Food Addit Contam Part Chem Anal Control Expo Risk Assess 34, 404-420.

13. Liao C, Tan Y, Wu C et al. (2016) City level of income and urbanization and availability of food stores and food service places in China. PLoS One 11, e0148745.

14. Popkin BM (2014) Nutrition, agriculture and the global food system in low and middle income countries. Food Policy $\mathbf{4 7}$, 91-96.

15. Hua J, Seto E, Li Y et al. (2014) Development and evaluation of a food environment survey in three urban environments of Kunming, China. BMC Public Health 14, 235.

16. Popkin BM, Adair LS \& Ng SW (2012) Global nutrition transition and the pandemic of obesity in developing countries. Nutr Rev 70, 3-21.

17. Gómez MI \& Ricketts KD (2013) Food value chain transformations in developing countries: selected hypotheses on nutritional implications. Food Policy 42, 139-150.

18. Sibhatu KT \& Qaim M (2017) Rural food security, subsistence agriculture, and seasonality. PLoS One 12, e0186406.

19. Gelli A, Donovan J, Margolies A et al. (2019) Value chains to improve diets: diagnostics to support intervention design in Malawi. Glob Food Secur 25, 100321.

20. GloPan (2016) Food Systems and Diets: Facing the Challenges of the 21st Century. London: Global Panel on Agriculture and Food Systems for Nutrition (GloPan). http://glopan.org/sites/default/files/ForesightReport.pdf (accessed April 2020).

21. Headey DD, Hirvonen K, Hoddinott J et al. (2019) Rural food markets and child nutrition. Am J Agric Econ 101, 1311-1327.

22. Zezza A \& Tasciotti L (2010) Urban agriculture, poverty, and food security: empirical evidence from a sample of developing countries. Food Policy 35, 265-273.

23. Bixby H, Bentham J, Zhou B et al. (2019) Rising rural bodymass index is the main driver of the global obesity epidemic in adults. Nature 569, 260-264.

24. Downs SM, Ahmed S, Fanzo J et al. (2020) Food environment typology: advancing an expanded definition, framework, and methodological approach for improved characterization of wild, cultivated, and built food environments toward sustainable Diets. Foods $\mathbf{9}, 532$.

25. Grätz T (2009) Moralities, risk and rules in West African artisanal gold mining communities: a case study of Northern Benin. Small-Scale Min Poverty Dev Sub-Sahar Afr 34, 12-17.

26. Hilson G \& Garforth C (2013) 'Everyone Now is Concentrating on the Mining': drivers and implications of rural economic transition in the Eastern Region of Ghana. J Dev Stud 49, 348-364.

27. Hilson G (2009) Small-scale mining, poverty and economic development in sub-Saharan Africa: an overview. Resour Policy 34, 1-5.

28. Maconachie R (2012) Diamond mining, urbanisation and social transformation in Sierra Leone. J Contemp Afr Stud 30, 705-723

29. Werthmann K (2009) Working in a boom-town: female perspectives on gold-mining in Burkina Faso. Resour Policy 34, 18-23.

30. Barrett CB, Christiaensen L, Sheahan M et al. (2017) On the structural transformation of Rural Africa. J Afr Econ 26, i11-i35. 
31. FAO (2016) Influencing Food Environments for Healthy Diets. Rome: Food and Agriculture Organization of the United Nations.

32. Swinburn BA, Sacks G, Hall KD et al. (2011) The global obesity pandemic: shaped by global drivers and local environments. Lancet 378, 804-814.

33. Glanz K, Sallis JF, Saelens BE et al. (2007) Nutrition Environment Measures Survey in Stores (NEMS-S): development and Evaluation. Am J Prev Med 32, 282-289.

34. Turner C, Aggarwal A, Walls H et al. (2018) Concepts and critical perspectives for food environment research: a global framework with implications for action in lowand middle-income countries. Glob Food Secur 18, 93-101.

35. Engler-Stringer R, Le H, Gerrard A et al. (2014) The community and consumer food environment and children's diet: a systematic review. BMC Public Health 14, 522.

36. Caspi CE, Sorensen G, Subramanian SV et al. (2012) The local food environment and diet: a systematic review. Health Place 18, 1172-1187.

37. Gamba RJ, Schuchter J, Rutt C et al. (2015) Measuring the food environment and its effects on obesity in the United States: a systematic review of methods and results. J Community Health 40, 464-475.

38. Gustafson A, Hankins S \& Jilcott S (2012) Measures of the consumer food store environment: a systematic review of the evidence 2000-2011. J Community Health 37, 897-911.

39. Fuster M, Messer E, Houser RF et al. (2013) Local notions of healthy eating and national dietary guidelines: a comparison in vulnerable Salvadoran Communities. Food Foodways 21, 288-314.

40. Kimoto R, Ronquillo D, Caamaño MC et al. (2014) Food, eating and body image in the lives of low socioeconomic status rural Mexican women living in Queretaro State, Mexico. Health Place 25, 34-42.

41. Chaudhari LS, Begay RC \& Schulz LO (2013) Fifteen years of change in the food environment in a rural Mexican community: the Maycoba project. Rural Remote Health 13, 2404.

42. Gupta V, Downs SM, Ghosh-Jerath S et al. (2016) Unhealthy fat in street and snack foods in low-socioeconomic settings in India: a case study of the food environments of rural villages and an urban slum. J Nutr Educ Behav 48, 269-279.e1.

43. World Bank (2013) Artisanal and Small-Scale Mining (Internet). http://www.worldbank.org/en/topic/extractivein dustries/brief/artisanal-and-small-scale-mining (accessed December 2020).

44. Sylla M (2017) Présentation Globale (Overview Presentation). Presentation at Atelier De Restitution des Rapports des Etudes Diagnostiques de L'exploitation Artisanale de L'or en République de Guinée (Dissemination Workshop on Diagnostic Studies on Artisanal Gold Mining in Guinea). Conakry, Guinea.

45. Cisse K (2017) Volet Economique (Economic Aspects). Atelier De Restitution des Rapports des Etudes Diagnostiques de L'exploitation Artisanale de L'or en République de Guinée (Dissemination Workshop on Diagnostic Studies on Artisanal Gold Mining in Guinea). Conakry, Guinea.

46. Kamano P (2017) Diagnostique Sociale (Social Diagnostic). Atelier De Restitution des Rapports des Etudes Diagnostiques de L'exploitation Artisanale de L'or en République de Guinée (Dissemination Workshop on Diagnostic Studies on Artisanal Gold Mining in Guinea). Conakry, Guinea.

47. Hilson G (2012) Family hardship and cultural values: child labor in malian small-scale gold mining communities. World Dev 40, 1663-1674.

48. ILO (2005) The Burden of Gold: Child Labour in Small-Scale Mines and Quarries. World of Work. Geneva: International Labour Organization.

49. Buss D, Rutherford B, Hinton J et al. (2017) Gender and Artisanal and Small-Scale Mining in Central and East
Africa: Barriers and Benefits. Montreal: Institute for the Study of International Development, McGill University.

50. Fisher E, Mwaipopo R, Mutagwaba W et al. (2009) 'The ladder that sends us to wealth': artisanal mining and poverty reduction in Tanzania. Small-Scale Min Poverty Dev Sub-Sahar Afr 34, 32-38.

51. Maconachie R (2011) Re-agrarianising livelihoods in post-conflict Sierra Leone? Mineral wealth and rural change in artisanal and small-scale mining communities. J Int Dev 23, 1054-1067.

52. INS \& ICF (2018) Enquête Démographique et de Santé en Guinée 2018 (Guinea Demographic and Health Survey 2018). Conakry, Guinea; Rockville, MD: Institut National de la Statistique (National Statistics Institute) (INS) et ICF.

53. Dabo A (2015) The impact of bauxite mining on the health of women and children in Sangaredi (Guinea-West Africa). MA Thesis, Indiana University. https://www.proquest.com/ openview/544b63085902e3a9cdaf214df576fbe2/1 (accessed August 2017).

54. Aragón FM \& Rud JP (2016) Polluting industries and agricultural productivity: evidence from mining in Ghana. Econ J 126, 1980-2011.

55. Jul-Larsen E, Kassibo B, Lange S et al. (2006) Socio-Economic Effects of Gold Mining in Mali. A Study of the Sadiola and Morila Mining Operations. Bergen: Christian Michelsen Institute.

56. Ofosu G, Dittmann A, Sarpong D et al. (2020) Socioeconomic and environmental implications of Artisanal and Small-Scale Mining (ASM) on agriculture and livelihoods. Environ Sci Policy 106, 210-220.

57. de Brauw A, Mueller V \& Lee HL (2014) The role of rural-urban migration in the structural transformation of Sub-Saharan Africa. World Dev 63, 33-42.

58. Kelly PF (2011) Migration, agrarian transition, and rural change in Southeast Asia: introduction. Crit Asian Stud 43, 479-506.

59. Fotso J-C (2007) Urban-rural differentials in child malnutrition: trends and socioeconomic correlates in sub-Saharan Africa. Health Place 13, 205-223.

60. Kandala N-B, Madungu TP, Emina JB et al. (2011) Malnutrition among children under the age of five in the Democratic Republic of Congo (DRC): does geographic location matter? BMC Public Health 11, 261.

61. Wegenast T \& Beck J (2020) Mining, rural livelihoods and food security: a disaggregated analysis of sub-Saharan Africa. World Dev 130, 104921.

62. Keita S (2001) Study on Artisanal and Small-Scale Mining in Mali. London: International Institute for Environment and Development.

63. Tschakert P (2009) Recognizing and nurturing artisanal mining as a viable livelihood. Small-Scale Min Poverty Dev Sub-Sahar Afr 34, 24-31.

64. Maconachie R (2014) Dispossession, exploitation or employment? Youth livelihoods and extractive industry investment in Sierra Leone. Futur Small-Scale Min Sub-Sahar Afr 62, 75-82.

65. Maconachie R (2009) Diamonds, governance and 'local' development in post-conflict Sierra Leone: lessons for artisanal and small-scale mining in sub-Saharan Africa? Small-Scale Min Poverty Dev Sub-Sahar Afr 34, 71-79.

66. Maconachie R \& Binns T (2007) 'Farming miners' or 'mining farmers'? Diamond mining and rural development in postconflict Sierra Leone. Chang Faces Rural Popul 23, 367-380.

67. Hirvonen K, Bai Y, Headey DD et al. (2020) Affordability of the EAT-Lancet reference diet: a global analysis. Lancet Glob Health 8, E59-E66.

68. ATLAS.ti (2017) Berlin: ATLAS.ti Scientific Software Development GmbH. https://atlasti.com/.

69. StataCorp LLC (2017) Stata Statistical Software: Release 15. College Station, TX: StataCorp LLC. 
70. FAO \& FHI360 (2016) Minimum Dietary Diversity for Women: A Guide for Measurement. Rome: Food and Agriculture Organization of the United Nations.

71. Coates J, Swindale A \& Bilinsky P (2007) Housebold Food Insecurity Access Scale (HFIAS) for Measurement of Household Food Access: Indicator Guide (v. 3). Washington, DC: FHI 360/FANTA.

72. Zhang LX, Koroma F, Fofana ML et al. (2020) Food security in artisanal mining communities: an exploration of rural markets in Northern Guinea. Foods 9, 479.

73. Stokes-Walters R, Fofana ML, Songbono JL et al. (2020) 'If you don't find anything, you can't eat': mining livelihoods and income, gender roles, and food choices in Northern Guinea. Resour Policy Rev 70, 101939.

74. Nordhagen S, Pries MA \& Dissieka R (2019) Commercial snack food and beverage consumption prevalence among children 6-59 months in West Africa. Nutrients 11, 11.

75. Aggarwal A, Monsivais P, Cook AJ et al. (2014) Positive attitude toward healthy eating predicts higher diet quality at all cost levels of supermarkets. J Acad Nutr Diet 114, 266-272.

76. Masters WA, Bai Y, Herforth A et al. (2018) Measuring the affordability of nutritious diets in africa: price indexes for diet diversity and the cost of nutrient adequacy. Am J Agric Econ 100, 1285-1301.

77. Bose I, Baldi G, Kiess L et al. (2019) The 'Fill the Nutrient Gap' analysis: an approach to strengthen nutrition situation analysis and decision making towards multisectoral policies and systems change. Matern Child Nutr 15, e12793.

78. Headey DD \& Alderman HH (2019) The relative caloric prices of healthy and unhealthy foods differ systematically across income levels and continents. J Nutr 149, 2020-2033.

79. Pries AM, Rehman AM, Filteau S et al. (2019) Unhealthy snack food and beverage consumption is associated with lower dietary adequacy and length-for-age z-scores among 12-23-month-olds in Kathmandu Valley, Nepal. J Nutr 149, 1843-1851.

80. Monteiro CA, Moubarac J-C, Cannon G et al. (2013) Ultra-processed products are becoming dominant in the global food system. Obes Rev 14, 21-28.

81. Monteiro CA, Levy RB, Claro RM et al. (2011) Increasing consumption of ultra-processed foods and likely impact on human health: evidence from Brazil. Public Health Nutr 14, 5-13.

82. Okoh G \& Hilson G (2011) Poverty and livelihood diversification: exploring the linkages between smallholder farming and artisanal mining in Rural Ghana. J Int Dev 23, $1100-1114$.

83. Cartier LE \& Bürge M (2011) Agriculture and artisanal gold mining in Sierra Leone: alternatives or complements? J Int Dev 23, 1080-1099.

84. Kamlongera PJ (2011) Making the Poor 'Poorer' or Alleviating Poverty? Artisanal mining livelihoods in Rural Malawi. J Int Dev 23, 1128-1139.

85. Mkodzongi G \& Spiegel S (2019) Artisanal gold mining and farming: livelihood linkages and labour dynamics after land reforms in Zimbabwe. J Dev Stud 55, 2145-2161.

86. De Jong TU \& Sauerwein T (2021) State-owned minerals, village-owned land: how a shared property rights framework helped formalize artisanal diamond miners in Côte d'Ivoire between 1986 and 2016. Resour Policy 70, 101920. 